\title{
The adjustment of goldfish to reduction in magnitude of reward in massed trials*
}

\author{
R. C. GONZALEZ, MARJORIE FERRY, and ALICE S. POWERS \\ Bryn Mawr College, Bryn Mawr, Pennsylvanio 19010
}

\begin{abstract}
For a group of goldfish trained in a runway under conditions of highly massed practice, reduction in magnitude of reward produced a gradual decline in performance to the level of a small-reward control group but no suggestion of negative successive contrast. These results are consistent with the suggestion that reward plays a somewhat different role in the learning of fish and rats. They also serve to extend the range of conditions under which the stimulus aftereffects of reward come to control the instrumental behavior of fish.
\end{abstract}

Negative successive contrast (Crespi, 1942; Elliott, 1928) has been sought in fish in three experiments, one involving a manipulative response (Lowes \& Bitterman, 1967 ) and the others a locomotor response (Gonzaiez, Potts, Pitcoff, \& Bitterman, 1972; Mackintosh, 1971). In each experiment, the fish failed to give evidence of the well established mammalian phenomenon. ${ }^{1}$ In two of the experiments, which were conducted under conditions of widely spaced practice [the intertrial interval (ITI) was $24 \mathrm{~h}$ ], the downshift in magnitude of reward produced no decrement whatsoever in performance (Gonzalez et al, 1972; Lowes \& Bitterman, 1967). In the other, under conditions of relatively massed practice (ITI $=3-5 \mathrm{~min}$ ), the downshift produced some suggestion of a gradual decline in performance, but the decline was not statistically significant and the observed difference between the downshifted group and a large-reward unshifted control group also failed to attain statistical significance (Mackintosh, 1971).

Although there is no reason as yet to believe that fish are capable of manifesting successive contrast, it is not unreasonable to expect that distribution of practice may importantly influence their performance in successive contrast situations. In massed as compared to spaced practice, the stimulus aftereffects of reward on a given trial may persist through the intertrial interval and come to play a role in the stimulus complex in which the animal subsequently is reinforced for responding. Capaldi (1967), on the basis of extensive work on the problem, has presented an elegant analysis of these discriminative-stimulus functions of reward aftereffects in rats, and the results of a recent experiment on patterning in goldfish demonstrate that such aftereffects may play a similar role in the control of instrumental responding in fish (Gonzalez, 1972). If large and small magnitudes of reward occasion distinctive stimuli $\left(\mathrm{S}^{\mathbf{R}_{\mathrm{L}}}\right.$ and $S^{R} S$ ) in fish, it is easy to see how their performance in massed trials may be affected by a downshift in magnitude of reward.

*This research was supported by NIMH Grant 15902. Requests for reprints should be sent to R.C. Gonzalez, Department of Psychology, Bryn Mawr College, Bryn Mawr, Pennsylvania 19010.
In the experiment to be reported here, three groups of goldfish were given five trials per day in a runway with an ITI of $15 \mathrm{sec}$. One group was reinforced with 40 Tubifex worms and another with 1 worm throughout the experiment. The third group was reinforced with 40 worms on the first 14 days of the experiment and with 1 worm on the remaining 21 days. The purpose of the experiment was to determine whether, with this further massing of trials, the downshift in amount of reward would produce a decrement in response and, if so, whether it would be of sufficient abruptness and magnitude to yield negative successive contrast.

\section{METHOD}

Subjects

The Ss were 27 experimentally naive goldfish, 4-5 in. long, obtained from a local dealer and housed in individual 2-gal tanks set on open shelves in a temperature-controlled laboratory.

\section{Apparatus}

For the purpose of this experiment, the second section of a double runway constructed for fish (Gonzalez \& Petersen) ${ }^{2}$ was employed. The section consisted of a start compartment (10 in. long), an alley ( 31 in. long), and a goal compartment (10 in. long) that was fixed at a 90-deg angle to the end of the alley and entered by a left turn. The entire unit was made of $1 / 2-$ in. black Plexiglas, with walls 6 in. high, and had hinged lids made of light-diffusing Plexiglas. (All dimensions given are for the inside of the apparatus.) The apparatus was filled with water (which was changed daily) to a depth of 4 in. A guillotine door $\left(D_{1}\right)$ controlled entrance into the alley from the start compartment. Opening $D_{1}$ tripped a microswitch mounted on the door frame, which activated two elapsed time meters. The first meter was stopped by S's interruption of any one of a column of three light beams 12 in. beyond $D_{1}$, yielding a measure of initial time (in $0.1 \mathrm{sec})$; the second meter was stopped by S's interruption of a second column of light beams 6 in. beyond the left turn into the goal compartment, yielding a measure of total time. Interruption of the second set of light beams also activated a feeder that discharged live Tubifex worms into the goal compartment through a small opening in the lid, $1.5 \mathrm{in}$. from the far end of the compartment. Attached to the far end of the goal compartment was a thin sheet of white Plexiglas that provided a contrasting background to facilitate detection of the reward. 


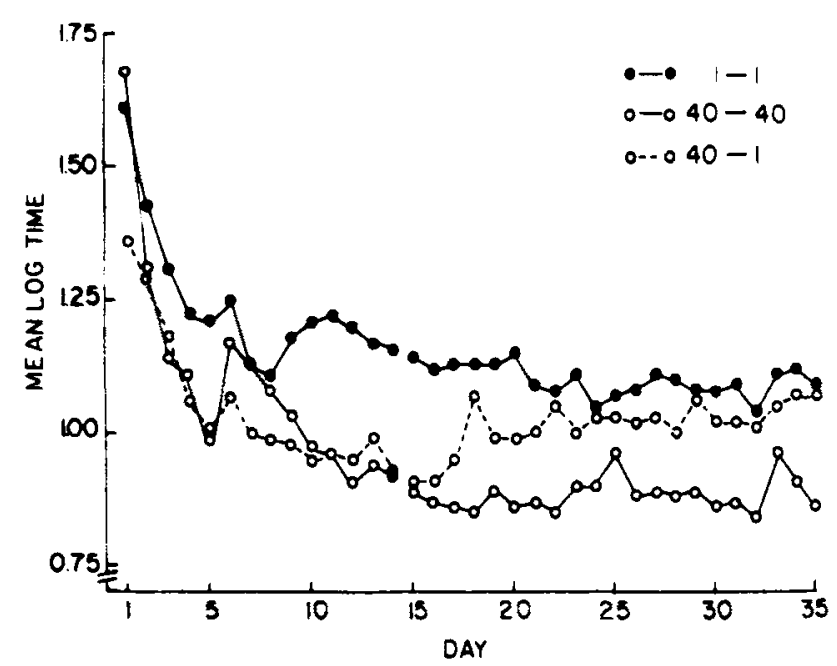

Fig. 1. The adjustment of goldfish to a downshift in reward magnitude in massed trials.

\section{Procedure}

The Ss were placed on a 24-h feeding schedule of dry food and, after adjustment to the laboratory, they were given experience with Tubifex worms introduced into their home tanks with a medicine dropper. Then there were several days of adjustment to handling, on each of which $S$ was scooped up from its home tank in a small container of clear Plexiglas, carried to the area of the room in which the apparatus was located, and then returned to its home tank and fed Tubifex worms. On each of the following 2 days, each $S$ was carried in the Plexiglas container to the goal compartment, and a prescribed number of worms was discharged from the feeder. After it had eaten the worms, $\mathrm{S}$ was scooped out of the goal compartment and, after $15 \mathrm{sec}$, given a second goal compartment feeding, after which it was returned to its home tank. For nine randomly selected Ss, these goal compartment feedings were of 1 worm each; for the remaining Ss, they were of 40 worms each. The final stage of preliminary training consisted of two reinforced runway trials, separated by a $15-\mathrm{sec}$ ITI, with the appropriate magnitude of reward ( 1 or 40 worms).

Throughout the experiment proper, each $\mathbf{S}$ was given five reinforced runway trials per day, with a 15 -sec ITI. In the first stage of the experiment, which lasted 14 days, the 1-worm Ss were reinforced with 1 worm on each trial and the 40-worm Ss with 40 worms. On each trial, $S$ was placed in the start compartment with $D_{1}$ closed and $D_{2}$ open. The trial began with the opening of $D_{1}$ by the $E$ and ended with the interruption of the second set of light beams by $S$, after which $D_{2}$ was closed. $S$ was scooped out of the goal compartment as soon as it had eaten the food and remained in the Plexiglas container filled with water for $15 \mathrm{sec}$, after which it was placed in the compartment for the start of the next trial. After the fifth trial of each day, $S$ was returned to its home tank. On the basis of their performance on this first (preshift) stage of the experiment, the 40-worm animals were divided into two matched groups of nine Ss each: Group 40-40 and Group 40-1.

The second (postshift) stage of the experiment lasted 21 days. On each trial, the 1-worm animals (Group 1-1) and the Ss of Group 40-1 were reinforced with 1 worm; the Ss of Group 40-40 continued to be reinforced with $\mathbf{4 0}$ worms. In all other respects, the procedure was identical to that of the first stage. Throughout both stages of the experiment, the total daily ration of food for all Ss was the same: 205 worms plus a small amount of dry food. That portion not earned in the apparatus was postfed in S's living tank $30 \mathrm{~min}$ after each daily session.

\section{RESULTS}

In Fig. 1, the preshift and postshift performance of the three groups is shown in terms of mean log total time on each day of the experiment. (The start time measure yielded the same pattern of results and is not, therefore, presented in the interest of conserving space. For Group 1-1, the data are based on seven Ss, two having been lost in the early days of Stage 1.) In the 14 days of preshift training, the curves declined in negatively accelerated fashion to terminal levels that differed in terms of magnitude of reward. A repeated-measures analysis of variance yielded significant effects of groups $(\mathrm{F}=3.44$, df $=2 / 22, \mathrm{p}=.05)$ and of days $(F=29.00, d f=13 / 286, p<.01)$; the interaction of Groups by Days fell short of significance at the $5 \%$ level $(F=1.50, d f=26 / 286, .05<p<.06)$. For the final 7 days of preshift training, the differences among the three groups were significant $(F=4.39, d f=2 / 22$, $p<.05$ ), and subsequent orthogonal comparisons showed that the times for Group 1-1 were significantly greater than those for the two 40-worm groups combined $(F=8.78, d f=1 / 22, p<.01)$, which did not differ from each other $(F<1)$.

The postshift curves show that the superiority of Group $40-40$ over Group 1.1 was maintained over the subsequent 21 days of the experiment and that the downshift in reward for Group 40-1 produced a gradual decrement in performance to the level of the 1 -worm control, with no suggestion of contrast (overshooting the control level). A repeated-measures analysis of variance for the three successive blocks of 7 days of postshift training yielded a significant interaction of Groups by Days $(F=4.57, \mathrm{df}=4 / 44, \mathrm{p}<.01)$; neither the effect of groups $(F=2.65, \mathrm{df}=2 / 22, \mathrm{p}>.05)$ nor the effect of blocks $(F<1)$ was significant. For the final block of 7 days, orthogonal comparisons showed that the difference between Group 40-40 and Groups 40-1 and $1-1$ combined was significant $(F=4.92, d f=1 / 66$, $\mathrm{p}<.05)$; the difference between Group 40-1 and Group $1-1$ was not significant $(F<1)$.

\section{DISCUSSION}

The results of this experiment show that, for fish at least, distribution of practice is an important variable in successive contrast situations. In a previous spaced trials experiment, a 40 to 1 reduction in number of units of reward produced no decrement whatsoever in performance (Gonzalez et al, 1972). In the present massed trials experiment, the same 40 to 1 reduction also failed to produce negative successive contrast, but it did lead to a gradual decline in performance to the level of the small-reward control.

It has been argued (Gonzalez et al, 1972) that the differences between fish and rats that have appeared in experiments on successive contrast and on resistance to 
extinction as a function of magnitude of reward (Gonzalez \& Bitterman, 1967; Gonzalez, Potts, Pitcoff, \& Bitterman, 1972; Lowes \& Bitterman, 1967; Mackintosh, 1971) suggest that reward plays a different role in the instrumental learning of the two animals. The notion is that the behavior of fish can be accounted for simply in terms of the operation of the strict principle of reinforcement (Thorndike, 1911; Hull, 1943), according to which reward acts directly to strengthen behavior in a given situation. In rats, rewards, like other stimuli, rather than strengthening behavior directly seem to be learned about and to influence behavior as anticipated consequences (incentives) of response.

The present results are in accord with this contention. If the behavior of fish is regulated in terms of the strict principle of reinforcement, then, in spaced trials, once the strength of connection for the large-reward animals exceeds the asymptote of the small reward, there is no means by which a downshift in magnitude of reward can produce a change in their performance. In massed trials, however, the conditions (e.g., magnitude) of reinforcement can be represented as stimuli at the start of each trial-the stimulus aftereffects of reward $\left(S^{R} L=\right.$ large reward, $S^{R} S=$ small reward) carry over the brief intertrial interval to form part of the stimulus situation to which the subsequent response is strengthened by the consequent reinforcement-and changes in these conditions can, by stimulus generalization, come to alter the strength of the tendency to respond. Capaldi (1967) has introduced the term "responsivity" to characterize the parameter of rate at which generalization decrement, or stimulus change (e.g., from $S^{R} L$ to $S^{R} S$ ), occurs from trial to trial, assuming that it can take a value from 0 (no change) to 1.0 (change from $S^{R} L$ to $S^{R} S$ after a single exposure to the new reward magnitude). Since, with a downshift in magnitude of reward, the reinforcing effects of the new reward magnitude are taking effect at the same time as its stimulus properties are producing generalization decrement, the gradual adjustment of the downshifted group of the present experiment to the level of the small-reward control group can be taken to reflect the gradual change in the composition of their habit (from $S^{R_{L}} H_{R}$ to $S^{R} S_{H}$ ) together with the gradual strengthening of the new habit to the level of that developed by the small-reward control group, which was reinforced from the outset for response in the presence of $\mathrm{S}^{\mathrm{R}} \mathrm{S}$.

Mackintosh (1971) has attempted to account for the differences between fish and rats that have appeared in experiments on resistance to extinction as a function of magnitude of reward and on shifts in magnitude of reward in terms of Capaldi's theory on the assumption that fish simply are less "responsive" than rats to changes in the conditions of reinforcement. In Capaldi's theory, negative successive contrast is the product of generalization decrement associated with reward aftereffects, and the extent of the decrement, other things equal, is a function of the degree of responsivity to change in the aftereffects of reward. Recently, Capaldi (1972) has distinguished between two properties of reward aftereffects, one of which is short-lived and functions only in massed trials (stimulus trace) and the other of which persists over long periods of time and is independent of intertrial interval (memory trace). Furthermore, he has concluded that the major source of generalization decrement in experiments on successive contrast is associated with the short-lived stimulus traces of reward. Since it follows that generalization decrement should be greater in massed than in spaced trials, the fact that the behavior of fish is altered by a downshift in magnitude of reward in massed but not in spaced trials is consistent with this conception. It does not follow from the theory, however, that even under the presumed optimal conditions of highly massed training fish do not show successive contrast. Either the theory is incorrect about the mechanism of contrast or some hypothesis of species difference such as Mackintosh's in terms of degree of responsivity must be invoked to account for the failure of fish to show contrast.

Although there is every reason to believe that the stimulus traces of reward play an important role in the control of behavior-and the data on patterning in fish and on the effect of distribution of practice on their adjustment to downshift in reward magnitude are perfectly understandable in terms of the carryover of such traces-there is considerable room for doubt that generalization decrement is the mechanism of successive contrast. The most prevalent view, in fact, is that the phenomenon is the product of emotionality arising from unconfirmed expectancy of reward. Indeed, the rather widespread rejection of the theoretical law of effect in favor of the view that rewards exercise their effects as anticipated consequences of response was stimulated in large measure by the demonstration of successive contrast in rats. The basic difference between fish and rats, in our view, is precisely in the expectational or anticipational role played by reward in rats. No evidence of such a role in fish has yet been uncovered.

\section{REFERENCES}

Capaldi, E. J. A sequential hypothesis of instrumental learning. In K. W. Spence and J. T. Spence (Eds.), The psychology of learning and motivation: Advances in research and theory. Vol. 1. New York: Academic Press, 1967. Pp. 67-156.

Capaldi, E. J. An analysis of the role of reward and reward magnitude in instrumental learning. In J. H. Reynierse (Ed.), Current issues in animal learning: $A$ colloquam. Lincoln: University of Nebraska Press, 1970. Pp. 357-389.

Capaldi, E. J. Successive negative contrast effect: Intertrial interval, type of shift, and four sources of generalization decrement. Journal of Experimental Psychology, 1972, 96, 433438.

Crespi, L. P. Quantitative variation in incentive and performance in the white rat. American Journal of Psychology, 1942, 55, 467-517.

Elliott, M. H. The effect of change of reward on the maze performance of rats. University of California Publications in Psychology, 1928, 4, 19-30. 
Gonzalez, R. C. Patterning in goldfīsh as a function of magnitude of reinforcement. Psychonomic Science, 1972, 28, 53-55.

Gonzalez, R. C., \& Bitterman, M. E. Partial reinforcement effect in the goldfish as a function of amount of reward. Journal of Comparative \& Physiological Psychology, 1967, 64, 163-167.

Gonzalez, R. C.. Potts, A., Pitcoff, K., \& Bitterman, M. E. Runway performance of goldfish as a function of complete and incomplete reduction in amount of reward. Psychonomic Science, 1972, 27, 305-307.

Hull, C. L. Principles of behavior. New York: Appleton-Century-Crofts, 1943.

Lowes, G., \& Bitterman, M. E. Reward and learning in the goldfish. Science, $1967,157,455-457$

Mackintosh, N. J. Reward and aftereffects of reward in the iearning of goldfish. Journal of Comparative \& Physiological Psychology, 1971, 76, 225-232.

Raymond, B., Aderman, M., \& Wolach, A. H. Incentive shifts in goldfish. Journal of Comparative \& Physiological Psychology,
$1972,78,10-13$.

Thorndike, E. L. Animal intelligence. New York: Macmillan, 1911.

\section{NOTES}

1. Another experiment that also failed to yield successive contrast in fish (Raymond, Aderman, \& Wolach, 1972) must be discounted because of some methodological inadequacies, which have been considered elsewhere (Gonzalez, Potts, Pitcoff, \& Bitterman, 1972).

2. Gonzalez, R. C., \& Petersen, F. Frustrative nonreward in fish. In preparation.

(Received for publication June 11, 1973; accepted September 6, 1973.) 